\title{
Information literacy across levels - best practice reports from higher education
}

\author{
Anne Sissel Vedvik Tonning1, Eystein Gullbekk², Therese S Skagen², Maria Carme Torras \\ Calvo $^{1}$
}

${ }^{1}$ University of Bergen; ${ }^{2}$ University of Oslo

Contact:

e-mail: post@noril.uib.no

\section{EDITORIAL}

\begin{abstract}
This issue of Noril contains articles in the best practice section, and has been in the review process for some time now. The authors have been patient and for that the editors are grateful. We have received papers relevant to information literacy from worldwide. The first paper is authored by Mette Bønløkke, Else Kobow and Anne-Kirstine Kristensen. They give a Danish perspective on the importance of collaboration between library and faculty for the development of information literacy programs which are integrated into the students' curriculums. Engere and Gudiksen are proposing information literacy in a critical psychology framework, conceptualizing individual learning primarily as an activity-based concept. The next article is an example from Morocco where Aziz el Hassani describes the start of a journey of implementing the information literacy thinking at a university. The Finnish contribution by Kristiina Hintikka and Ann-Louise Paasio is about how they developed and completed an information literacy course for doctoral students in cooperation with faculties, and the challenges they met. In the paper from Nigeria the author Luke 0. Obasuyi writes about how first year students cope with information and communication technology, and information literacy skills. The Swedish paper, authored by Peter Kåhre, takes the reader into the ongoing debate of the librarians' role in the educational processes. At last, but not least, you can read the English article by Andrew Walsh that encourages play as a strategy for students' to develop information literacy.
\end{abstract}

Enjoy! 